For a delivery into the vein at $99^{\circ}-100^{\circ}$ with summer heat conditions using a tubing $2 \frac{1}{3}$ yards long, a cistern elevation from the vein of 3 feot, and a cannula with a bore which gives 2 ounces of saline per minute in a jet $3-4$ inches high; the temperature at which the cistern saline will require to be maintained will be found to be between $106^{\circ}-108^{\circ}$.

As to the procedure for infusion, the filter candle (scrubbed, tested, and sterilised) is filled by hanging on the side of the Glevated cistern (filled with saline at the appropriate temperature), the rubber tubing is then attached in situ, and the tube is milked till a current is established. All contained air is then removed by placing the candle slantwise bodily in the container and raising the tubing to form an upward curve, using both hands. As the right hand progresses with the air along the tube the left depresses the tubing emptied of air to prevent its return, and this procedure is continued till the uptilted cannula is reached. The candle is then inverted in the cistern and the apparatus is ready for use; if a bubble-catcher is used inversion is not necessary.

\section{Intravenous Infusion.}

An adequate reaction proportionate to the degree of collapse must be looked for and assisted. This condition is never attained until the infusion reaction rigor (which occurs approximately when 5 pints have been infused) is well passed. The continuance of the saline infusion after the occurrence of the reaction rigor up to $8-10$ pints will procure the following benefits: 1 . Dilution of the blood. 2. Elevation of the blood pressure, with re-establishment of suppressed renal flow. 3. Elimination of the endotoxins from the blood and later from the stools, thus obviating the onset of the febrile reaction stage of cholera, the remainder of the illness being usually apyrexial. No apprehension need be felt at a rise of temperature to $103^{\circ}$ during the infusion in fact, this degree of temperature oscillation I conside the most favourable for cessation of infusion, provided that more than 6 pints have passed in. If pyrexia of $103^{\circ}$ is associated with the infusion of less than 6 pints, the temperature of the saline in the cistern should be lowered and the infusion continued.

Where the stools are sanious (a condition usually associated with a high rectal temperature) the saline should be infused at $98^{\circ}$ or less, and 5 or 6 pints used. Such cases need a specially careful treatment, the associated dysenteric condition being only benefited indirectly by the relief of the collapse.

Strangely enough, I have found marked collapse when it is due solely to the loss of blood fluids a favourable index in prognosis as showing an absence of febrile complications, and such cases, however profoundly collapsed, give excellent results. In such instances where the pulse is absent and death seems imminent, the rate of flow should be started at 4 ounces per minute, until the pulse returns. If delivery of saline to this extent cannot be obtained by elevating the cistern and using a cannula of a wider bore, a vein on the opposite side should be opened and fed from an additional candle which may be placed in the same container. Oa the return of the pulse to the wrist, one apparatus will be found sufficient to ensure reaction.

The associated conditions in this form of collapse are: (1) M trked plasticity of the skin ; (2) great backward swing of the budy heat, as evidenced by icy chilliness of the extremities, an oral temperature of $95^{\circ}-96^{\circ}$ and a rectal somewhat higher; (3) an unrecordable blood pressure; (4) a blood specific gravity in the neighbourhood of 1080 ; and (5) usually intense cramps. In such cases a marked rigor must be expected and hot-water bottles and blankets held in readiness, usually also a $1 / 40$ grain of morphia with 1/100 grain of atropine hypodermically will be found useful, after the rigor is passed.

The preparation of the vein selected is carried out in the usual way, no anæsthetic is necessary; the cannula is fixed in position by adhesive strapping, the arm placed on a splint and secared to a bedstead in anticipation of the muscular move. ments caused by the reaction rigor. Straw palliasses and tin floor-trays are advisable. If the hospital has a more or less permanent character a tin-floored transfusion-room is recommended.

That the reaction induced by saline transfusion may, to some extent, be due to a toxæmia induced by the endotoxins of water-borne bacilli used in the infusion is possible that it entirely accounts for the reaction rigor I do not believe. In any case, it will be interesting to see to what extent the phenomena of the infusion reaction will be modified by filtration previous to boiling.
REMARES ON THE

\section{CAUSE AND NATURE OF THE CHANGES WHICH OCCUR IN MUSCLE AFTER NERVE SECTION.}

\author{
BY J. N. LA N G L E Y, Sc.D., F.R.S.,
} PROFESSOR OF PHYSIOLOGY, CAMBRIDEE.

Two theories have been put forward to account for the obvious fact that section of a nerve causes trophic-i.e., nutritive-changes in the muscle it supplies. One is that there are special nervous impulses affecting nutrition different from those causing contraction. Since there is no independent evidence of the existence of such impulses, this theory has received little support. The other is that the maintenance of the nutritive condition of the muscle depends upon its contracting at intervals, so that when the normally occurring contractions are prevented by nerve section the nutritive condition of the muscle suffers, and it gradually loses weight and decreases in irritability. This theory has in its favour the fact that normally the size of muscles is, within certain limits, dependent upon exercise. In accordance with it the wasting of denervated muscle is spoken of as "disuse atrophy," and largely on the basis of this theory it is a common practice to induce contraction in paralysed muscles by stimulating them with condenser or galvanic currents. If this theory were true, a certain degree of contraction brought about by electrical stimulation would keep the denervated muscles in a normal condition. It need hardly be said that this never occurs in clinical practice. In man the degree to which electrical stimulation prevents wasting of the muscles cannot be determined with any accuracy. A few experiments on this point were recently made on rabbits by Professor Kato and myself. ${ }^{1}$ The tibial or peroneal nerves were cut on both sides and the paralysed muscles stimulated on one side with condenser currents. Taking the weight of the muscles on the unstimulated side as a standard, the percentage gain in weight on the stimulated side in the four experiments made was: 18 days, 0 ; 28 days, 22.9 per cent.; 36 days, 9.8 per cent. ; 71 days, 10.3 per cent. These experiments, whilst suggesting that contraction delayed the wasting of the muscles, were not definitely in favour of the theory of "disuse atrophy," for in each experiment great wasting of the muscles occurred and the sluggish response to electrical stimulation characteristic of denervated muscle was not prevented. Further, the difference in weight on the two sides might possibly be due to individual variation, and I have since found variations up to about 7 per cent. in the weight of the muscles on the two sides in normal rabbits. ${ }^{2}$ In the experiments mentioned above, the extent of daily stimulation was not the same in the several experiments: it varied from less than, to about that usually applied in cases of man. The absenc $\lrcorner$ of decisive delay of atrophy might then be due to the degree of stimulation being insufficient. I have in consequence made two further experiments on rabbits, in one stimulatiog for about $2 \frac{1}{2}$ hours a day for rather more than three weeks and in the other extending and flexing the limb for a like period. In neither case was there any certain delay in the wasting of the muscles.

Since, then, contraction of the muscles neither for a short daily period nor for a long daily period prevents the wasting of the muscles nor the occurrence of sluggish contraction, I conclude that the changes which take place in muscles after nerve sections are not due to absence of contraction, and that the term "disuse atrophy" is a misnomer. In this case we have to look for some other cause of the atrophic and other degenerative changes. It was noticed by Professor Kato and myself that muscles from about the fourth day after section of their nerves are in a state of continuous fibrillation-i.e. the separate muscle fibres contract rhythmically, but with different rhythms ; the muscles present a shimmering appearance when viewed by light reflected from their surface. The contractions cause no movement of the muscle as a whole,

1 Journal of Physiology, xlix., p. 432, 1915.
I It may be mentioned that it is necessary to examine the muscles and 2 It may be mentioned that it is necessary to examine the muscles and
bones for signs of previous injuries. Thus in one case in which the bones for signs of previous injuries. Thus in one case in which the side was heavier than that on the side with nerve intact but on examination of the bones on this side a large callus was found indicating that the lower leg had at some time been broken, an 7 that the muscles that the lower leg had at some time been broken, a
in consequence had not obtained their proper size. 
and are easily overlooked; possibly they could be shown in man by the use of the string galvanometer. As each fibre contracts many times a minute the total expenditure of energy in the day must be considerable. It is, then, I think, reasonable to suppose that this continued activity of the muscle fibres must cause fatigue, and that the atrophy of muscle is due to too great rather than to too little functional activity. The changes in reaction which occur in denervated muscle are, in fact, like those caused by fatigue. I have, however, not found any definite evidence that the stimulation is harmful. With regard to this, it has to be borne in mind that contraction drives on lymph and tends to prevent the accumulation of metabolic products. It may also cause an after-increase of the blood flow, and in the later stages of paralysis at any rate when the blood-vessels have recovered tone, this would no doubt be beneficial. But on the whole it appears to me probable that it would be better to obtain these accessory results of contraction without the contraction itself. And in the recent discussion on Dr. F. HernamanJohnson's paper on the use of condensers in the treatment of nerve lesions ${ }^{3}$ Dr. F. P. Cumberbatch states that he has obtained good results by the use of sinusoidal alternating currents not causing contraction.

There are two points I would comment on with regard to the reaction of denervated muscle to electrical stimulation.

1. Cases were early noticed in man in which, after nerve severance, voluntary power may return before the response to faradic currents, and in the recent use of condenser currents it has been found that voluntary power may return without a return of response to condenser shocks of short duration.

It has long been known that in the early stage of regeneration, tetanising currents applied above the point where the ends of the severed nerve were united will cause contraction whilst similar currents applied below it have no, or less, effect. Some instances of this in the limb nerves are given by Howell and Huber, ${ }^{4}$ together with earlier references, and I have found a similar condition after joining the vagus to the cervical sympathetic. ${ }^{5}$ The result has been spoken of as showing that nerve fibres in regeneration recover conductivity before irritability. The difference is probably one of difference of response to currents of different duration, and to this may be attributed the return of voluntary power before return of response to currents of short duration.

2. The fact that faradic currents as applied in testing the reaction of muscles in man cease to cause contraction four to seven days after nerve severance, whilst recognised as partly due to the disappearance of nerve irritability, is often taken as showing that the muscle fibres themselves have lost their irritability to faradic currents. In support of this view it has been urged that in animals the effect of the nerves may be abolished by curari, without abolishing the faradic irritability of the muscles, so that in man the disappearance of the latter must be due to a change in the muscles. But several observers have noted response to faradic stimulation in the exposed muscles of animals several weeks, at any rate, after denervation, and $I$ have obtained it in the exposed muscles of the rabbit at all times up to 10 weeks, the longest period I have tried. In consequence I should attribute the absence of response which occurs in man to the currents employed being too weak.

I have not made sufficient experiments to be certain of the progress of decrease of irritability to induced currents in denervated muscle, but, so far as my experiments go, it is slow and gradual. In lower vertebrates the irritability of muscle fibres is greater in the region near the nerve-endingthe neural region-than in otber parts of the fibre, and no doubt the same is the case in the mammal. In this case the extent of the contraction on stimulating the denervated muscle directly will depend on the position of the electrode with regard to the neural regions of the muscle fibres. In general, most of the neural regions lie in an oblique band somewhere near the middle of the muscle, and are absent in the end portions.

It is possible that a sudden drop of irritability occurs in the neural region in the later stages of denervation; I have not noticed this in my experiments, but some recent observations of Professor Noel Paton and Dr. L. Findlay ${ }^{\circ}$ suggest its occurrence when galvanic currents are used.

3 Proc. Roy. Soc. Med., Surgical Sect. 1916. p. 1: The Laveet, Feb. 12th. 1916, p. 351. "Journal of Physiology. xiii.. p. 364, 1892. 5 Ibid., xxi1i., p. 251, 1899 . 6 Ibir., 1, p. 193, i916.
THE DIAGNOSIS OF CANCER OF THE STOMACH. ${ }^{1}$

BY JAMES ALEXANDER LINDSAY, M.D. R.T.I., F.R.C.P. LoxD.,

PROFESSOR OF MEDICINE IN THE QUEEN'S UNIVERSITY OF BELTAST.

CANCER of the stomach is from several points of view one of the most important conditions which claim our attention. It is important from its frequency. The stomach comes next to the nterus as the seat of cancer. Cancer of the stomach accounts for 1.5 per cent. of all deaths occurring in hospital practice. It is important because early diagnosis is often a matter of extreme difficulty, and also of the greatest importance, if operative intervention is to have any fair prospect of success. It is important, finally, because to suggest to a patient an unfounded suspicion of cancer is one of the most serious and unfortunate of errors.

During the last 14 years 40 cases of cancer of the stomach have occurred in my practice at the Royal Victoria Hospital. I am much indebted to my assistant, Dr. S. I. Turkington, for the careful manner in which he has collected and collated this material for me. I shall confine myself to the diagnostic problem, leaving the question of operative measures in the very capable hands of Mr. A. B. Mitchell.

1. Age of patients. - No cuse occurred under 30 years of age. Fourth decade, 5 cases, $12 \frac{1}{2}$ per cent. ; fifth decade, 7 cases, $17 \frac{1}{2}$ per cent. ; sixth decade, 19 cases, $47 \frac{1}{2}$ per cent. ; seventh decade, 8 cases, 20 per cent.; over 70 , 1 case, $2 \frac{x}{2}$ per cent. These figures are in accord with general experience. The disease falls mainly upon the fifth, sixth, and seventh decades of life, with a slight preponderance in the sixth decade. Cases are not unknown in earlier life. The disease is not rare at advanced ages.

2. Sex.-Males, 23 ; females, 17 . Most observers report a preponderance in the male sex. The proportion is usually given as 5 to 4 , which is in close correspondence with my own figures. Some authorities report a considerably higher proportion of males, while Fenwick thinks that the sexes suffer equally. The Registrar.General's Reports for England and Wales (1901-1909) show that in males cancer of the stomach accounts for 214 per cent. of all deaths from cancer, but in females the figure is only $14 \cdot 2$.

3. Family history. - There was a clear family history of cancer in 4 cases-i.e., in 10 per cent. In a fifth case there was a history of doubtful " gastric disease." One woman stated that her husband had died of cancer. In the remaining 34 cases the family history was unimportant.

4. Personal history.-A history of previous gastric ulcer was obtained in only 5 cases-i.e., $12 \frac{1}{2}$ per cent. There is a curious, almost disconcerting, discrepancy between physicians and surgeons as to the frequency with which simple gastric ulcer precedes gastric cancer. Habershon found this sequence in only 5 cases out of 340 . Fenwick puts the proportion at 3 per cent. Osler found the sequence in 4 cases out of 150 . On the other hand, Mayo puts the proportion at 54 per cent. and Moynihan at 72 per cent. This is a very important matter from several points of view. If the higher figures are correct we shall be compelled to regard the remote dangers of gastric ulcer much more seriously than we have hitherto done. Further, physicians have been in the habit of regarding the comparatively abrupt development of painful dyspepsia after the age of 40 as one of the most significant indications of commencing gastric cancer. It is evident that if simple ulcer is a common antecedent of gastrio cancer this rule will fail us. It is not easy to reconcile the higher figures with the preponderance of cancer in the male sex, nor with the marked contrast between the results of the examination of the gastric contents in the two conditions. My figures support the views of Habershon, Fenwick, and Osler.

Four patients gave a history of alcoholic excess. Osler found this history in 8 cases out of 150. There is no reason to conclude that alcoholism is a factor in the causation of gastric cancer.

In 26 out of my 40 cases the previous digestion of the patients was reported to be good.

5. Mode of onset and initial symptoms. - "Signal symptom 